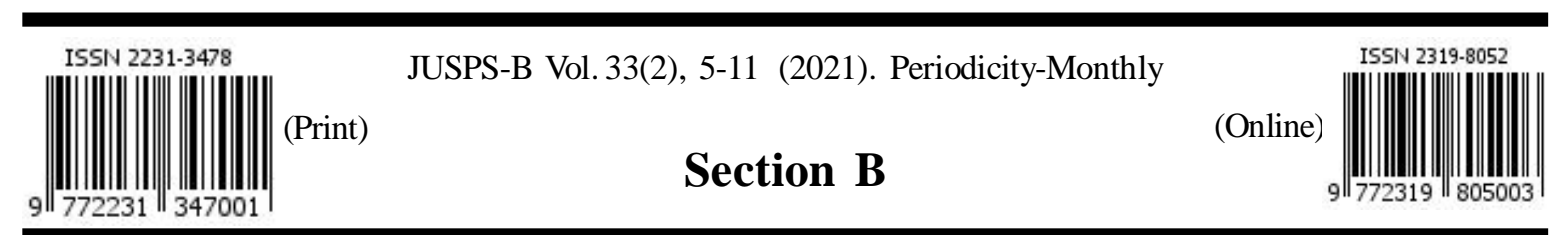

JOURNAL OF ULTRA SCIENTIST OF PHYSICAL SCIENCES
Estd. 1989

\title{
Study of thermo-acoustical properties of Liquid mixtures of Aqueous solution of Lithium Chloride and Lithium Hydroxide at Different Temperatures
}

\author{
NEERAJ RATHORE and AJAY KUMAR SINGH* \\ Department of Physics, Bareilly College, Bareilly, U P. -243005 (India) \\ Corresponding Author E-mail: aksnmr@gmail.com \\ http://dx.doi.org/10.22147/jusps-B/330201
}

Acceptance Date 07th August, 2021,

Online Publication Date 13th August, 2021

\begin{abstract}
Density, viscosity and ultrasonic velocity of the various compositions of liquid mixtures of aqueous solutions of Lithium chloride $(\mathrm{LiCl})$ and Lithium hydroxide $(\mathrm{LiOH})$ have been experimentally measured at $303,308,313$ and $318 \mathrm{~K}$ and at atmospheric pressure. From these experimental measurements the acoustic impedance (Z) and adiabatic compressibility $\left(\beta_{\mathrm{ad}}\right)$ have been calculated. The variations in these parameters have been correlated to derive the intermolecular interactions taking place between the mixtures of present study.

Key words : Viscosity, Ultrasonic velocity, Adiabatic compressibility and Acoustic impedance.

\section{Introduction}

A large number of research work has been carried in the field of thermo-acoustical studies to understand the intermolecular interactions with some basic parameters such as ultrasonic velocity, density and viscosity. These are very essential parameters for providing information about nature of molecular interactions and structural aspects ${ }^{1-3}$. Ultrasonic investigation techniques find extensive applications in characterizing various aspects of thermodynamical and physiochemical behaviour of various liquids and liquid mixtures. The measurement of ultrasonic speed and some allied parameters derived from it, has been used in understanding the nature of intermolecular interactions in liquid mixtures by many workers ${ }^{4-5}$. Liquid mixtures rather than single pure liquids are of utmost practical importance in most chemical and industrial processes as they provide the wide range of mixtures of two or more components in varying proportions so as to permit continuous adjustment of the derived properties of the medium. Lithium salts like, Lithium chloride ( $\mathrm{LiCl})$ and Lithium hydroxide $(\mathrm{LiOH})$ have significant importance in industrial as well as medicinal applications.
\end{abstract}

This is an open access article under the CC BY-NC-SA license (https://creativecommons.org/licenses/by-nc-sa/4.0) 
The aim of present study is to investigate the variation of thermo acoustical parameters of binary liquid mixture of aqueous solutions of Lithium chloride and Lithium hydroxide with molar concentrations and temperatures. The variation of these parameters with molar concentration may be helpful in pharmaceutical studies.

\section{Material and Methods}

Aqueous solution $(1 \mathrm{~N})$ of $\mathrm{LiCl}$ and $\mathrm{LiOH}$ were prepared with double distilled water. The chemicals used were of analytical grade (Merk > 99\%). The solutions were left for sufficient time to allow them to have complete ionization. The binary mixtures of desired compositions were prepared by mixing known volumes of two prepared solutions. The ultrasonic velocities were measured at $2 \mathrm{MHz}$ with a single crystal variable path interferometer (F-81 D Mittal make) with an accuracy of $0.01 \%$. The densities of aqueous solutions and mixtures were measured with a pycnometer of bulb volume $10 \mathrm{cc}$. The viscosity of the liquids was measured by an Ostwald Viscometer.

The density and ultrasonic velocity for all binary mixtures were measured experimentally. Various acoustic parameters like, adiabatic compressibility $\left(\beta_{a d}\right)$ and specific acoustic impedance $(Z)$ were evaluated from the measured values of ultrasonic velocity $(u)$ and density $(\rho)$ using following relations ${ }^{6,7}$

$$
\begin{aligned}
& u=\lambda f \\
& \beta_{a d}=\frac{1}{u^{2} \rho} \\
& Z=u \rho
\end{aligned}
$$

where $\lambda$ is wave length, $f$ is the frequency of ultrasonic wave, and $\rho$ is the density of solution.

\section{Results and Discussion}

The experimental values of density, ultrasonic velocity, viscosity, adiabatic compressibility and acoustic impedance with the varying mole fractions of the binary mixture and with the varying temperature are presented in tables 1 to 5 . The variations of these parameters with varying mole fraction are also presented in figure 1 to 5 for the binary mixtures.

Table-1. Values of Density $\left(\mathrm{gm} / \mathrm{cm}^{3}\right)$ for the binary mixture of $\mathrm{LiCl} \& \mathrm{LiOH}$ with varying mole fraction

\begin{tabular}{c|c|c|c|c|c}
\hline \multicolumn{2}{c|}{ Mole fraction } & \multicolumn{4}{c}{ Temperature K } \\
\hline $\mathrm{LiCl}$ & $\mathrm{LiOH}$ & $303 \mathrm{~K}$ & $308 \mathrm{~K}$ & $313 \mathrm{~K}$ & $318 \mathrm{~K}$ \\
\hline 1.0 & 0.0 & 1.01773 & 1.01608 & 1.01422 & 1.01215 \\
\hline 0.9 & 0.1 & 1.01825 & 1.01654 & 1.01463 & 1.01254 \\
\hline 0.8 & 0.2 & 1.01880 & 1.01695 & 1.01505 & 1.01296 \\
\hline 0.7 & 0.3 & 1.01941 & 1.01743 & 1.01549 & 1.01339 \\
\hline 0.6 & 0.4 & 1.01995 & 1.01782 & 1.01588 & 1.01379 \\
\hline 0.5 & 0.5 & 1.02049 & 1.01829 & 1.01631 & 1.01420 \\
\hline 0.4 & 0.6 & 1.02100 & 1.01874 & 1.01675 & 1.01464 \\
\hline 0.3 & 0.7 & 1.02160 & 1.01918 & 1.01714 & 1.01502 \\
\hline 0.2 & 0.8 & 1.02215 & 1.01958 & 1.01758 & 1.01545 \\
\hline 0.1 & 0.9 & 1.02271 & 1.02001 & 1.01798 & 1.01587 \\
\hline 0.0 & 1.0 & 1.02324 & 1.02049 & 1.01841 & 1.01626 \\
\hline
\end{tabular}


Neeraj Rathore, et al., JUSPS-B Vol. 33(2), (2021).

Table-2. Values of Ultrasonic Velocity $(\mathrm{m} / \mathrm{s})$ for the binary mixture of $\mathrm{LiCl} \& \mathrm{LiOH}$ with varying mole fraction

\begin{tabular}{c|c|c|c|c|c}
\hline \multicolumn{2}{c|}{ Mole fraction } & \multicolumn{4}{c}{ Temperature K } \\
\hline $\mathrm{LiCl}$ & $\mathrm{LiOH}$ & $303 \mathrm{~K}$ & $308 \mathrm{~K}$ & $313 \mathrm{~K}$ & $318 \mathrm{~K}$ \\
\hline 1.0 & 0.0 & 1566.873 & 1574.055 & 1581.636 & 1586.424 \\
\hline 0.9 & 0.1 & 1569.868 & 1577.247 & 1584.429 & 1588.020 \\
\hline 0.8 & 0.2 & 1572.858 & 1580.040 & 1586.823 & 1591.115 \\
\hline 0.7 & 0.3 & 1576.848 & 1583.626 & 1590.088 & 1594.005 \\
\hline 0.6 & 0.4 & 1579.242 & 1586.424 & 1592.409 & 1597.197 \\
\hline 0.5 & 0.5 & 1580.439 & 1585.227 & 1593.606 & 1598.394 \\
\hline 0.4 & 0.6 & 1585.626 & 1592.010 & 1597.596 & 1603.182 \\
\hline 0.3 & 0.7 & 1588.020 & 1594.803 & 1601.187 & 1606.773 \\
\hline 0.2 & 0.8 & 1590.015 & 1598.793 & 1603.980 & 1608.969 \\
\hline 0.1 & 0.9 & 1593.207 & 1601.988 & 1607.571 & 1611.960 \\
\hline 0.0 & 1.0 & 1596.798 & 1605.576 & 1610.364 & 1614.234 \\
\hline
\end{tabular}

Table-3. Values of Viscosity (centipoise) for the binary mixture of LiCl \& LiOH with varying mole fraction

\begin{tabular}{c|c|c|c|c|c}
\hline \multicolumn{2}{c|}{ Mole fraction } & \multicolumn{4}{c}{ Temperature K } \\
\hline $\mathrm{LiCl}$ & $\mathrm{LiOH}$ & $303 \mathrm{~K}$ & $308 \mathrm{~K}$ & $313 \mathrm{~K}$ & $318 \mathrm{~K}$ \\
\hline 1.0 & 0.0 & 0.8519 & 0.7889 & 0.7227 & 0.6849 \\
\hline 0.9 & 0.1 & 0.8452 & 0.7916 & 0.7254 & 0.6828 \\
\hline 0.8 & 0.2 & 0.8620 & 0.7988 & 0.7450 & 0.6976 \\
\hline 0.7 & 0.3 & 0.8624 & 0.7947 & 0.7501 & 0.7052 \\
\hline 0.6 & 0.4 & 0.8699 & 0.8140 & 0.7623 & 0.7055 \\
\hline 0.5 & 0.5 & 0.8653 & 0.8061 & 0.7498 & 0.6901 \\
\hline 0.4 & 0.6 & 0.8918 & 0.8313 & 0.7702 & 0.7134 \\
\hline 0.3 & 0.7 & 0.8945 & 0.8316 & 0.7777 & 0.7282 \\
\hline 0.2 & 0.8 & 0.9135 & 0.8461 & 0.7851 & 0.7332 \\
\hline 0.1 & 0.9 & 0.9326 & 0.8606 & 0.7926 & 0.7382 \\
\hline 0.0 & 1.0 & 0.9456 & 0.8562 & 0.8024 & 0.7424 \\
\hline
\end{tabular}

Table-4. Val ues of Adiabatic Compressi bility $\left(\times 10^{-10} \mathrm{Kg}^{-1} \mathrm{~ms}^{2}\right)$ for the binary mixture of $\mathrm{LiCl} \& \mathrm{LiOH}$ with varying mole fraction

\begin{tabular}{c|c|c|c|c|c}
\hline \multicolumn{2}{c|}{ Mole fraction } & \multicolumn{4}{c}{ Temperature K } \\
\hline $\mathrm{LiCl}$ & $\mathrm{LiOH}$ & $303 \mathrm{~K}$ & $308 \mathrm{~K}$ & $313 \mathrm{~K}$ & $318 \mathrm{~K}$ \\
\hline 1.0 & 0.0 & 4002 & 3973 & 3941 & 3926 \\
\hline 0.9 & 0.1 & 3985 & 3954 & 3926 & 3916 \\
\hline 0.8 & 0.2 & 3968 & 3939 & 3912 & 3899 \\
\hline 0.7 & 0.3 & 3954 & 3919 & 3895 & 3884 \\
\hline 0.6 & 0.4 & 3931 & 3905 & 3882 & 3867 \\
\hline 0.5 & 0.5 & 3932 & 3908 & 3883 & 3870 \\
\hline 0.4 & 0.6 & 3895 & 3873 & 3854 & 3835 \\
\hline 0.3 & 0.7 & 3881 & 3958 & 3835 & 3816 \\
\hline 0.2 & 0.8 & 3870 & 3937 & 3822 & 3804 \\
\hline 0.1 & 0.9 & 3852 & 3820 & 3801 & 3789 \\
\hline 0.0 & 1.0 & 3833 & 3802 & 3786 & 3776 \\
\hline
\end{tabular}


Table-5. Values of Acoustic Impedance $\left(\times 10^{3} \mathrm{~kg} / \mathrm{m}^{2} / \mathrm{sec}\right.$.) for the binary mixture of $\mathrm{LiCl} \& \mathrm{LiOH}$ with varying mole fraction

\begin{tabular}{c|c|c|c|c|c}
\hline \multicolumn{2}{c|}{ Mole fraction } & \multicolumn{4}{|c}{ Temperature K } \\
\hline LiCl & LiOH & $303 \mathrm{~K}$ & $308 \mathrm{~K}$ & $313 \mathrm{~K}$ & $318 \mathrm{~K}$ \\
\hline 1.0 & 0.0 & 1594.5 & 1599.1 & 1604.0 & 1605.5 \\
\hline 0.9 & 0.1 & 1598.3 & 1603.2 & 1607.5 & 1607.8 \\
\hline 0.8 & 0.2 & 1602.3 & 1606.7 & 1610.6 & 1611.6 \\
\hline 0.7 & 0.3 & 1603.9 & 1611.1 & 1614.4 & 1615.2 \\
\hline 0.6 & 0.4 & 1610.6 & 1614.2 & 1617.5 & 1618.9 \\
\hline 0.5 & 0.5 & 1610.5 & 1614.0 & 1617.4 & 1618.6 \\
\hline 0.4 & 0.6 & 1618.8 & 1621.7 & 1624.1 & 1626.5 \\
\hline 0.3 & 0.7 & 1622.3 & 1625.2 & 1628.4 & 1630.8 \\
\hline 0.2 & 0.8 & 1625.1 & 1629.8 & 1631.9 & 1633.6 \\
\hline 0.1 & 0.9 & 1629.3 & 1633.9 & 1636.2 & 1637.3 \\
\hline 0.0 & 1.0 & 1633.7 & 1638.2 & 1639.9 & 1640.3 \\
\hline
\end{tabular}

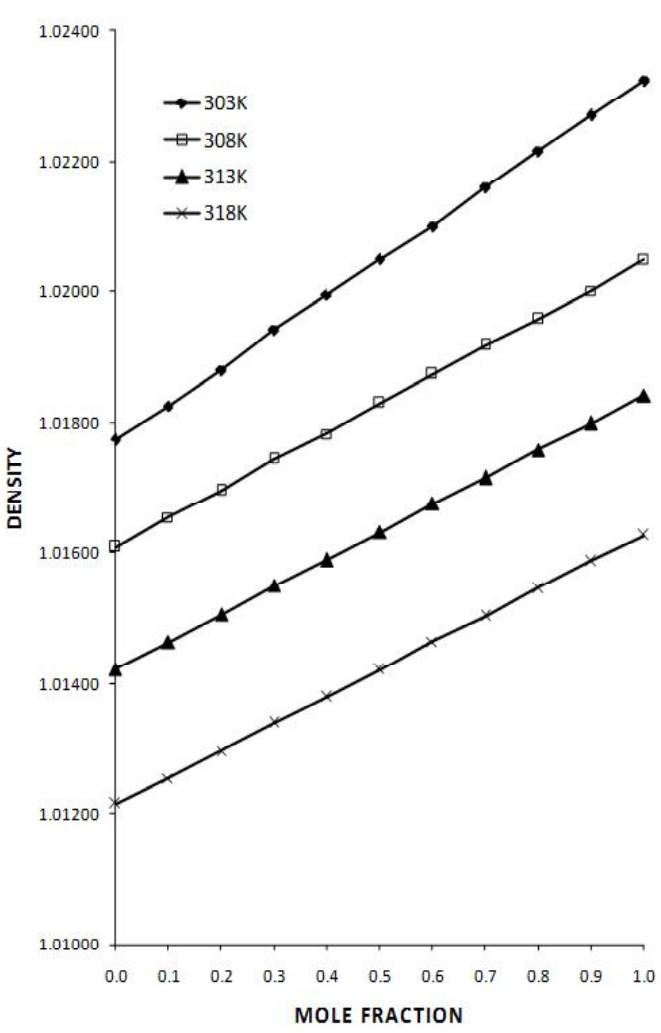

Figure 1: Variation of Density $\left(\mathrm{gm} / \mathrm{cm}^{3}\right)$ for the binary mixture of $\mathrm{LiCl} \& \mathrm{LiOH}$ with varying mole fraction

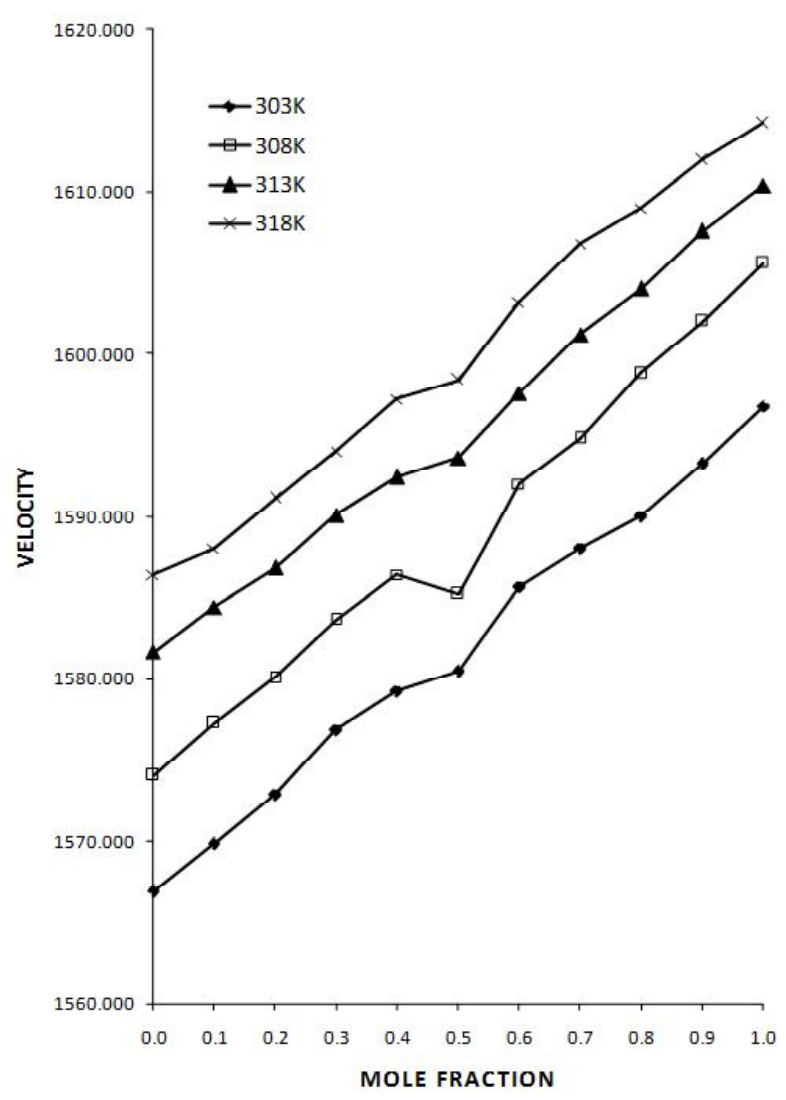

Figure 2: Variation of Ultrasonic Velocity $(\mathrm{m} / \mathrm{s})$ for the binary mixture of $\mathrm{LiCl} \& \mathrm{LiOH}$ with varying mole fraction 


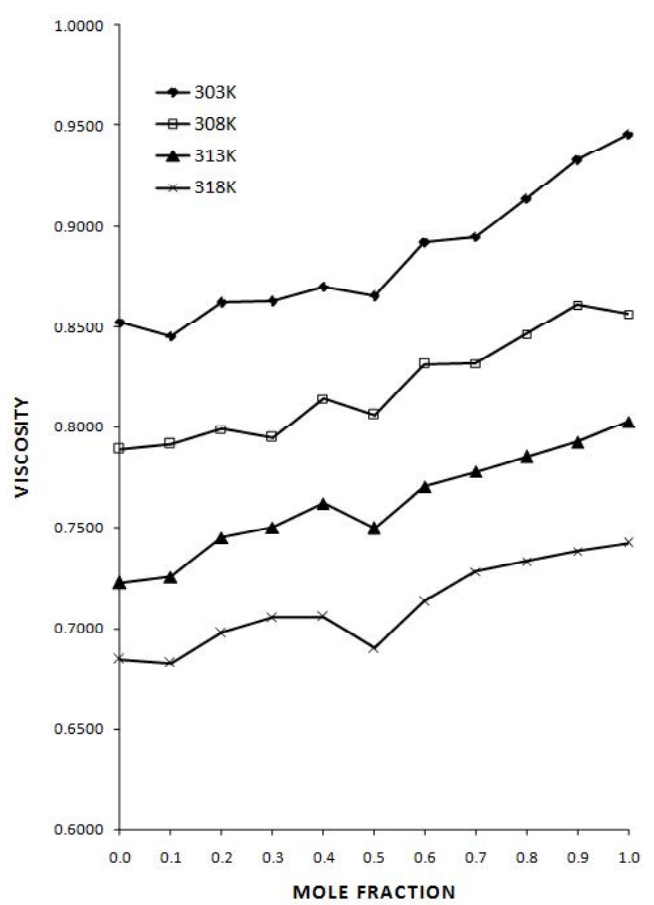

Figure 3: Variation of Viscosity (centipoise) for the binary mixture of $\mathrm{LiCl} \& \mathrm{LiOH}$ with varying mole fraction

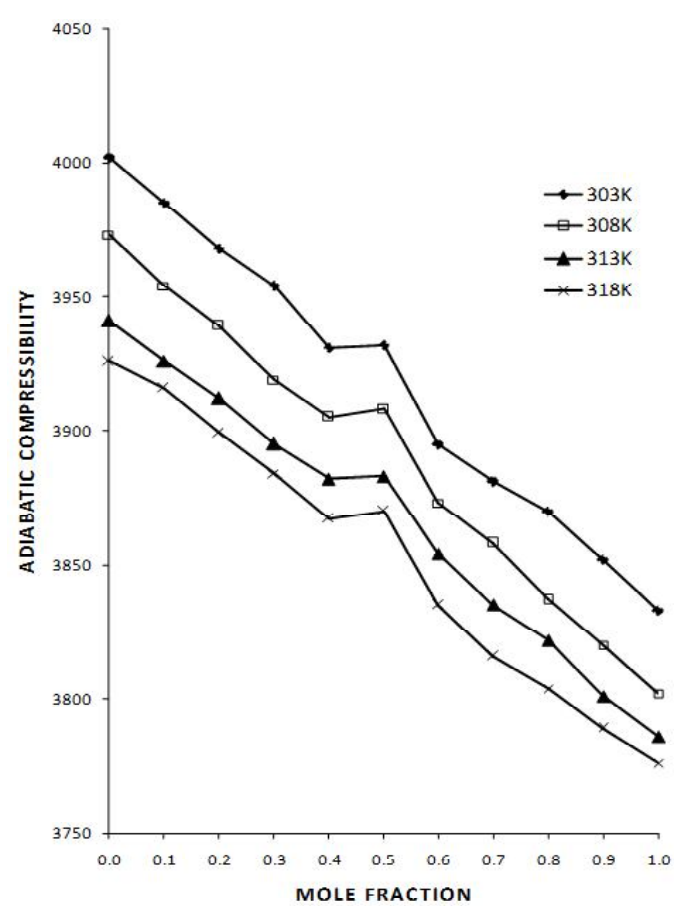

Figure 4: Variation of Adiabatic Compressibility $\left(\times 10^{-10} \mathrm{Kg}^{-1} \mathrm{~ms}^{2}\right)$ for the binary mixture of $\mathrm{LiCl} \&$ $\mathrm{LiOH}$ with varying mole fraction

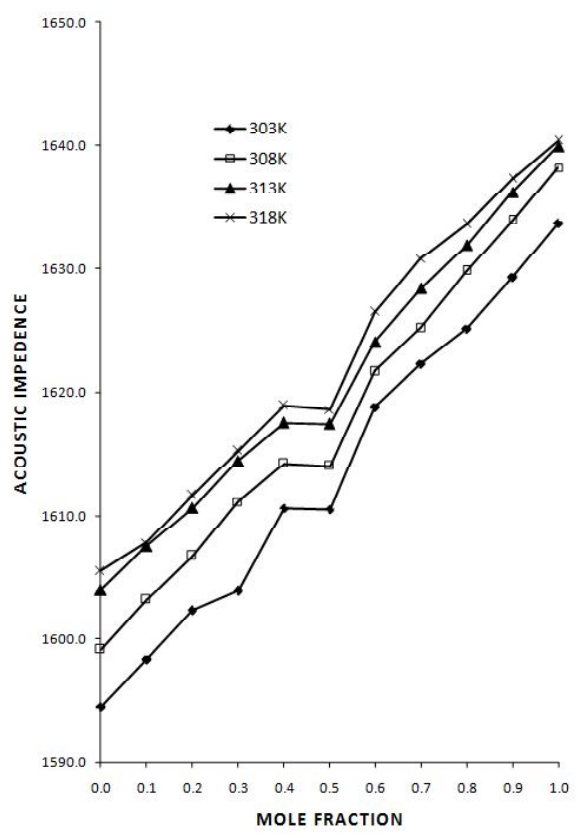

Figure 5: Variation of Acoustic Impedance $\left(\times 10^{3} \mathrm{~kg} / \mathrm{m}^{2} / \mathrm{sec}\right.$. ) for the binary mixture of LiCl \& LiOH with varying mole fraction 


\subsection{Density :}

The density of binary mixture increases linearly as the mole fraction of $\mathrm{LiOH}$ is increased in solution. Figure 1 shows that the variation of density with mole fraction of $\mathrm{LiOH}$ is almost linear. The density increases due to the increase in number of heavier oxide ions in mixture ${ }^{8}$. As the temperature is increased the density of mixture gets decreased.

\subsection{Ultrasonic velocity:}

The ultrasonic velocity as indicated in figure 2 is found increasing non-linearly with increasing mole fraction of LiOH indicating that the ultrasonic velocity increases with density of solution but at the specific mole fraction 0.5 of $\mathrm{LiOH}$ the ultrasonic velocity decreases, probably at this mole fraction, a complex is formed that does not allow the ultrasonic wave to travel freely in the solution and hence the ultrasonic velocity decreases. On further increasing the mole fraction of $\mathrm{LiOH}$ (above 0.5 ) the velocity increases nonlinearly. The increase in the velocity at this specific mole fraction shows some significant interaction between the solute and solvent molecules. The similar behaviour has earlier been reported by some other workers ${ }^{9,10}$.

\subsection{Viscosity:}

Viscosity increases non linearly with increasing the mole fraction of LiOH. The increase in viscosity of the solution on increasing salt concentration is confirmed by some researchers ${ }^{11,12}$. At mole fraction 0.5 of $\mathrm{LiOH}$ the viscosity shows a sudden decrease in its value. On increasing the temperature, the viscosity of mixture decreases for all mole fractions and the amount by which the viscosity suddenly decreases at complex forming mole fraction 0.5 is more at higher temperature.

\subsection{Adiabatic compressibility:}

The adiabatic compressibility $\left(\beta_{a d}\right)$ is a measure of inter molecular association or repulsion due to the presence of unlike molecules in the solution ${ }^{13,14}$. The variation of adiabatic compressibility with mole fraction of $\mathrm{LiOH}$ is shown in figure 4. The compressibility decreases with increasing mole fraction of $\mathrm{LiOH}$ in the solution and attains a sudden rise at 0.5 mole fraction of $\mathrm{LiOH}$. On further increasing the mole fraction it starts decreasing. The reverse behaviour of compressibility occurs because of the structural changes present in the mixtures, that bring the molecules to a close packing ${ }^{15}$. The presence of velocity maxima and compressibility maxima at same mole fraction of $\mathrm{LiOH}$ supports the existence of complex formation through hydrogen bonding to be maximum at that concentration.

\subsection{Acoustic impedance :}

When ultrasonic wave travels through a solution certain part of it travels through the solution and rest gets reflected by the ions. The characteristic that determines the backward movement of wave is known as acoustic impedance $(\mathrm{Z})^{16,17}$. As shown in figure 5 the acoustic impedance is found to increase with increasing mole fraction of $\mathrm{LiOH}$ in solution. The higher impedance indicates the presence of bulkier solvated (LiOH) ions, due to ion-solvent interaction that restricts the free flow of ultrasonic wave. The variation of acoustic impedance (Z) further proves the formation of complex at (0.5) mole fraction of $\mathrm{LiOH}$.

\section{Conclusions}

The nonlinear variation of ultrasonic velocity and associated acoustical parameters gives the idea of solute-solvent interaction and complex formation in the binary mixture of $\mathrm{LiCl}$ and $\mathrm{LiOH}$. The variation of ultrasonic velocity with temperature indicates breaking of hetero and homo association of molecules in the binary liquid mixtures. The strong association of $\mathrm{LiCl}$ and $\mathrm{LiOH}$ at 0.05 molar concentration may be helpful in 
JUSPS Vol. 33(2)B, (2021).

pharmaceutical and food industries to prepare various drug dosages, solution, tablets, capsule, gel and injection in solution form.

\section{References}

1. Pal A., Kumar H, Arbad, B. R. and Tekal,e A. B., Ultrasonic speeds and isentropic functions of mixtures of N-methyl-2-pyrrolidinone and branched alcohols at 298.15 K, Ind. J Pure. Appl. Phys., 41, 113, (2003).

2. Rastogi, M., Awasthi. A., Gupta, M. and Shukla, J.P. Molecular association of aliphatic ketones and phenol in a non-polar solvent - Ultrasonic and IR study, J. Mol. Liq., Vol.107, Nos.1-3,185-204, (2003).

3. Nikam, P. S., Mehdi, H. and Patil, V. U., Molicular interaction between aniline and n-alkanols (C5, C6 C7 C8 C10) molecules, An ultrasonic study, Ind. J. Pure Appl. Phys., 38, 693, (2000).

4. Reddy, B. R. and Reddy, D. L., Ultrasonic measurements in ethyl acetate and n-butanols, Ind. J Pure Appl. Phys., 37, 13-19, (1999).

5. Syal, V.K., Patial, B.S. and Chauhan S., 'Ultrasonic velocity,viscosity and density studies in binary mixtures of dimethyl formamide and ethyl methyl ketone at different temperatures', Ind. J. Pure Appl. Phys., Vol. 37, 366-370(1999).

6. Bansal R. K., A text book of Organic Chemistry; 2nd ed.; Willey Eastern Ltd., New Delhi, 477 (1990).

7. Ramanathan, K. and Ravichandran, S., Ultrasonic study of mixed salt solutions of ammonium and ammonium chloride solution. Ind. J. Pure App. Ultrason., 26, 12-17 (2004).

8. Chimankar, O.P., Shriwas, R.S. and Tabhane, V.A.; Intermolecular interaction studies in some aminoacids with aqueous $\mathrm{NaOH}$, Journal of Chem. and Pharm. Res., 3(3), 587-596, (2011).

9. Eshwarbhat, J., Manjunath M. N. and ShreeVaraprasad N. S., Acoustic behaviour of citric acid in aqueous and partial aqueous media, Ind. J Pure Appl. Phys., 48, 875, (2010).

10. Geetha, D. and Rakkapan, C., Ultrasonic studies on solutions of hydroxy propyl methyl cellulose phthalate in alcohols and acetone mixture, Ind. J Phys., 77B, 525-528, (2003).

11. Sudarmozhi G., Ramanathan K. and Ravichandran S., Ultrasonic studies in the mixture of Lithiumhydroxide and Lithum Sulphate, Proc. 15th Nat. Sym. Ultrasonics 85, (2006).

12. Kannappan, A. N. and Palani, R.; Studies on molecular interaction in ternary liquid mixtures by ultrasonic velocity measurement, Ind. J. Phys., 70B, 59-65, (1996).

13. Dange, S. P., Borkar, P. D. and Chimankar, O. P., Physico-chemical analysis on binary liquid mixture of Nicotinic acid at different temperatures, Indian J Pure Appl. Phys., 59, 32-137, (2021).

14. Nikam, P. S., Kapade, B. M., Hasan, M.; "Molecular interactions in binary mixtures of bromobenzene with normal alkanols (C-1-C-4): An ultrasonic study", Indian J Pure Appl. Phys., 38(3), 170-173, (2000).

15. Selvakumar, M. and Krishanabhat, D., Molecular interactions of polymethyl methacrylate and polyethyeleneglycol solutions in tetrahydrofuran, Indian J Pure Appl. Phys., 46, 712, (2008).

16. Sumathi T. and Maheshwari, U.; Ultrasonic and theoretical studies of some ternary liquid mixtures at various temperatures, Ind. J. Pure Appl. Phys., 47, 782, (2009).

17. Thorat, H. N. and Murugkar, A., Thermo-acoustical properties of carbamide and N, N-dimethylformamide binary mixture at different temperatures, Indian J Pure Appl. Phys., 58, 141-146, (2020). 